\begin{tabular}{|c|c|c|}
\hline & Int.J.Curr.Microbiol.App.Sci (2016) 5(12): 654-659 & \multirow{4}{*}{ 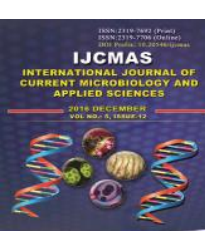 } \\
\hline & International Journal of Current Microbiology and Applied Sciences & \\
\hline & ISSN: 2319-7706 Volume 5 Number 12 (2016) pp. 654-659 & \\
\hline EXCELLENT & http://www.ijcmas.com & \\
\hline PUBLISHERS & & wwww.jemas.com \\
\hline
\end{tabular}

Original Research Article

http://dx.doi.org/10.20546/ijcmas.2016.512.073

\title{
Cervical Tubercular Lymphadenopathy, Clinical Course, Difficulties in Management and Resistance Pattern in Retreatment Cases
}

\author{
Munir Ahmad Wani ${ }^{1}$ and Ajaz Nabi Koul ${ }^{2 *}$ \\ ${ }^{1}$ Department of General Surgery, Sher-i-Kashmir Institute of Medical Sciences University, \\ Srinagar, Kashmir, India \\ ${ }^{2}$ Department of Medicine, Division of Infectious Diseases; Consultant Internist, \\ Sher-i-Kashmir Institute of Medical Sciences University, Srinagar, Kashmir, India \\ *Corresponding author
}

\begin{tabular}{|c|c|}
\hline & A B S T RA C T \\
\hline & \multirow{6}{*}{$\begin{array}{l}\text { Cervical lymphadenitis is one of the common modes of presentation in extra pulmonary } \\
\text { tuberculosis. It is easy to suspect and establish the diagnosis but a difficult course to } \\
\text { follow. It is even more perplexing to establish resolution of infection or document drug } \\
\text { resistance. The limiting factor remains frequent FNAC, while in pulmonary } \\
\text { tuberculosis sputum collection and its analysis is easy and non invasive. This } \\
\text { prospective study was undertaken on OPD basis in division of Infectious Diseases, } \\
\text { Department of Medicine, SKIMS, Kashmir. } 32 \text { patients of FNAC/ Biopsy proven } \\
\text { isolated cervical tuberculosis were included in this study. The mean age of presentation } \\
\text { was } 24.6+\text { + } 13.4 \text { years. } 12 \text { patients were males and } 20 \text { patients were females. The } \\
\text { common presentation was neck mass (100\%), fever (64\%), night sweats }(12 \%) \text {, cough } \\
\text { (3\%), Ill health (3\%). Diagnosis was established by FNAC and nodal biopsy were ever } \\
\text { necessary. In } 8(33 \%) \text { patients who were retreatment cases nodal material was sent for } \\
\text { molecular diagnosis to establish resistance. CBNAAT, line probe assay analysis } \\
\text { revealed INH resistance in } 3 \text { patients( } 9.3 \%) \text {, RMP resistance in } 2 \text { patients }(6.1 \%) \text { and } 3 \\
\text { patients(9.3\%) were sensitive to both INH and RMP. No documentation of MDRTB } \\
\text { was done. } 1 \text { patient was HIV positive amongst } 12 \text { patients tested for retrovirus in } \\
\text { relevant clinical context. All patients were treated with standard regime on daily basis. } \\
\text { Patients with resistance were treated as per standard drug regime. Cervical tubercular } \\
\text { lymphadenopathy is separate disease from pulmonary tuberculosis in terms of } \\
\text { diagnostic difficulty, paradoxical reactions, evaluation of clinical course, } \\
\text { documentation of cure and resistance. This study emphasizes that tubercular } \\
\text { lymphadenitis occurs in young patients with female preponderance. The study } \\
\text { advocated routine nodal sampling for molecular diagnostics in relevant clinical context. } \\
\text { The study wanted to highlight the limitation of repeated aspirations to establish cure or } \\
\text { resistance. }\end{array}$} \\
\hline Keywords & \\
\hline & \\
\hline Artic & \\
\hline & \\
\hline & \\
\hline
\end{tabular}

\section{Introduction}

Tuberculous lymphadenitis is among the most frequent presentations of extrapulmonary tuberculosis (TB). Tuberculous lymphadenitis in the cervical region is known as scrofula (WHO, 2015). In the United States, about 20 percent of patients with TB have extrapulmonary disease, and lymphadenitis is a presenting 
symptom in about 30 to 40 percent of cases (Singh et al., 2016).

The incidence of tubercular lymph node enlargement has appreciably increased with HIV burden. Despite appreciable progress in containing smear positive pulmonary tuberculosis the data on smear negative, extrapulmonary tuberculosis is not so encouraging.

Although suspecting and diagnosing cervical tubercular lymphadenopathy is less difficult but challenge in these patients is tracking clinical course and establishment of cure. A new issue is steadily cropping up, drug resistance in tubercular lymphadenopathy. Ideally drug sensitivity should be done in any patient of tuberculosis but should be done at least in retreatment cases.

The patients of cervical tubercular lymphadenopathy are relatively well preserved without major clinical symptoms or signs except nodal enlargement. The present study was undertaken in Infectious disease OPD in tertiary care hospital of Kashmir, India to study factors which can address approach towards patients with TB nodal enlargement, methods to track clinical course and ultimately establish cure. The present study is intended to check for resistance patterns in isolated TB adenitis in TB endemic area.

\section{Materials and Methods}

The present study included those patients who attended infectious disease OPD of SKIMS, Kashmir with cervical lymphadenopathy of varying duration. These patients underwent routine blood works especially blood counts, ESR, LDH, CRP, CxR, USG of neck, USG of abdomen or axillae where ever indicated. Patients were subjected to sputum for AFB, Urine for AFB and Mantoux testing.
All patients underwent FNAC of these nodes, and were ever it was inconclusive lymph node biopsy was done. Those patients who had etiology other than tuberculosis were excluded from the study. Those patients who had concomitant tuberculosis of any other organ were also excluded from the study. Patients with smear positive tuberculosis were also excluded from the study.

Those patients who had earlier tubercular cervical lymphadenopathy and had been treated with ATT variable number of times were included in the study and were subjected to molecular diagnostic testing to check status for drug resistance.

Those patients who had clinical suspicion of HIV/ AIDS were subjected to retroviral testing. The patients with definitive diagnosis were put on INH, RMP, ETHAM, PZA for 2 months and after documentation of resolution (clinically and sonologically) were continued with INH and RMP for next 4 months.

The patients who did not show definitive resolution of symptoms or signs at 2 months were extended drugs for 1 month with addition of Moxifloxacin. These patients were reassessed at 3 months and same procedure of sonologic documentation of resolution was adhered.

Patients with documentation of INH resistance were put on RMP, ETHAM, PZA for 9 months plus MOXI for initial 3 months. Patients with documentation of RMP resistance were treated with MOXI, PZA, INH and ETHAM for 9 months with inj KANNA for first 3 months.

\section{Results and Discussion}

32 patients of FNAC/biopsy proven cervical tubercular lymphadenopathy were included 
in present study. Males were12 patients $(37.5 \%)$ and females were 20 patients $(62.5 \%)$. The mean age of presentation was 24.6+_13.4 years. The common presentations were neck mass $(100 \%)$, fever (64\%), night sweats(12\%), cough(3\%), ill health(3\%). Blood counts revealed mean $\mathrm{Hb}$ of $11.4+3.2 \mathrm{mg} / \mathrm{dl}$ with normochromic normocytic anemia. Total leukocyte counts and platelets were normal. Mean ESR was $42+\_18 \mathrm{~mm}$. serum chemistry revealed LDH of 480+_62. KFT, LFT, uric acid were normal in all patients.

Sputum for AFB, urine for AFB, CxR, USG abdomen, USG bilateral axillae were normal in all patients. Mantoux was done in all patients and mean induration at 72 hours was $18+\_9 \mathrm{~mm}$. USG neck was main stay of imaging in all patients. 48 significant nodes were imaged in these patients.

\section{The findings on USG neck were following}

Number distribution; 1 node in 9 patients, 2 nodes in 13 patients, 3 nodes in 6 patients and more than 3 nodes in 4 patients.

Site distribution; 31 nodes were on right side of neck and 17 nodes on left side.

Size distribution; (mean transverse diameter) $>2$ to $5 \mathrm{cms} 33$ nodes, 5 to $8 \mathrm{cms}$ 14 nodes and more than $8 \mathrm{cms} 1$ node.

Sonologic description; discrete nodes were 47 and matted 1 node. Central necrosis was seen in 26 nodes, homogenous density in 22 nodes, well defined margins in 41 nodes, abscess formation in 6 nodes, matted 1 nodal group and draining sinus in 2 nodes.

FNAC was done in all patients after selection of single representative node. It was done by experienced pathologist under direct vision. Cytologically four different patterns were found.

1. epitheloid cell preponderance $(10 \%)$

2. gaint cell formation with caseous necrosis $(26 \%)$

3. granuloma formation with caseous necrosis $(24.7 \%)$

4. granuloma formation(39\%)

5. pus formation with mixed cellular infiltrate and gaint cell formation (.3\%)

Cervical nodal biopsy was done in 13 patients (40\%) who has evidence of granulomas formation, which could be present in many disorders. The biopsy excluded many patients who did not fit into diagnosis of tuberculosis but had granulomas due to some other conditions. The 13 patients under present consideration had caseous necrosis with granulomas formation.

8 patients with prior history of ATT intake and now again developed cervical tubercular lymphadenopathy were subjected to CBNAAT (line probe assay for RIF/INH resistance detection) on biopsy material. 3 patients $(9.3 \%)$ were resistant to $\mathrm{INH}, 2$ patients $(6.1 \%)$ were resistant to RMP and 3 patients $(9.3 \%)$ has infection sensitive to both INH and RMP.

1 patient was HIV positive amongst 12 patients tested for retrovirus, they were those patients whose clinical suspicion was high to be tested.

24 patients who were first time detected for tuberculosis were put on category $1^{\text {st }}$ drugs like INH+RMP+ETHAM+PZA for 2 months. At the end of 2 months patients 
were reevaluated with clinical improvement of symptoms, resolution of size of neck masses and USG documentation of decrease in size of the individual swellings necessitated change of drugs to INH and RMP for next 4 months. 5 patients amongst the above mentioned group did not show appreciable resolution of disease at 2 months were given additional Moxifloxacin for $3^{\text {rd }}$ month and then switched over to maintenance phase for next 4 months.

3 patients who were under previously treated category and had line probe assay sensitive to INH and RMP were treated with conventional regime. 3 patients who were resistant to INH were treated with RMP+ETHAM+PAZ+moxi for 9 months with documentation of resolution at completion of treatment.

2 patients with RMP resistance were treated with ing KANNA+MOXI+PZA+ETH for 3 months and then excluding kanna rest drugs continued for 9 months more months.

4 patients needed surgical debulking. 1 patient had developed abscess which needed surgical exploration, even partial resection of platysma muscle. 3 patients has extensive disease with in duration, amongst which one had $8 \mathrm{cms}$ matted group of nodes. 12 patients had IRIS like features at 4 weeks which ranged from $10 \%$ to $14 \%$ increase in transverse diameter but improved slowly by end of $8^{\text {th }}$ week.

Amongst them 2 patients had still increased size at $8^{\text {th }}$ week were included them amongst those 5 patients who needed prolongation of intensive phase of drug therapy with addition of Moxifloxacin.

2 patients developed drug induced hepatitis at $5^{\text {th }}$ week of therapy and were put on alternative therapy of ETHAM, KANNA,
MOXI till resolution of hepatitis and then sequentially replacing original drugs till completion of course.

All the patients were followed for 6 to 9 months after stopping of drugs. No relapse or treatment failure was documented in our series.

AFB positive tuberculosis can be followed for cure by documentation of AFB negativity or by recently developed CBNAAT methods. Such a mechanism cannot be applied to cervical tubercular lymph node enlargement. Here issued remain following,

1. The documentation of tuberculosis is dependent on FNAC/ biopsy which remain invasive procedure.

2. USG documentation of increase in size is not predictive of treatment failure. It can happen in IRIS or abscess formation, cold abscess tracking or coalescence of softened nodes. In addition USG is operater dependent.

3. Many times the material aspirated is scant which may not be enough to be subjected to CBNAAT.

4. Multiple FNACs during treatment course leads to lot of induration in surrounding tissue which after treatment leads to lot of fibrosis and disfigurement.

5.At times it is too difficult to convince operating surgeon for debulking surgery, as they are apprehensive for fistulisation.

All the patients were given standard antitubercular druga as per WHO recommendations on daily basis (Khan, 2009; Handa et al., 2012; Koul et al., 2012). Mantoux test was unreliable test. It had huge 
variability. Even some patients had gaint Mantoux.

The relapse cases were ill monitored as they were AFB negative, probably under qualified medical personnel were monitoring these patients. Such patients are off track from routine AFB positive pulmonary tuberculosis who have formulized pattern of management. All these 8 cases were given daily treatment regime.

The authors advocate daily regime in all cervical tuberculosis patients, monitored in tertiary care facility with highly qualified and motivated infectious disease personnel.

As we start to conquer drug sensitive pulmonary tuberculosis as evident by encouraging data from WHO in global TB report of 2015, smear negative $\mathrm{TB}$ and resistant $\mathrm{TB}$ are new diseases which are posing hurdles to medical fraternity.

Another factor which brings good outcome in such patients is motivated and cooperative surgical unit, which help in debulking of disease burden. It acts by two ways. One the quantity of disease is lessened morphologically and other is the penetration of drugs becomes easy and targeted.

A very important observation came from this study is that Moxifloxacin and kannamycin showed promising response in the patient recovery. We do accept the sample size is too small to derive at any conclusions but at the same time the paucity of $2^{\text {nd }}$ line drugs in resource limited place like ours the quinolone group especially flouroquionolones gives the clinician a little respite (Fontanilla et al., 2011; Jindal et al., 2013).

Another factor which needs to be highlighted in context of observations is that cervical TB adenitis involved younger age group with acceptable socioeconomic status and preserved anthropometric analysis. It prompts us to emphasize that TB especially of nodes is making its journey from havenots to haves.

\section{References}

Biswas, G., Das, A., Haldar, D., Mukherjee, A., Dutta, S., Sinha, R. 2013. Clinicopathological correlates of cervical lymphadenopathy: A hospital based study. Indian J. Otolaryngol. Head Neck Surg., 65 Suppl 1: 42-7.

Blaikley, J.F., Khalid, S., Ormerod, L.P. 2011. Management of peripheral lymph node tuberculosis in routine practice: An unselected 10-year cohort. Int. J. Tuberc. Lung Dis., 15: 375-8.

Fontanilla, J.M., Barnes, A., von Reyn, C.F. 2011. Current diagnosis and management of peripheral tuberculous lymphadenitis. Clin. Infect. Dis., 53: 555-62.

Handa, U., Mundi, I., Mohan, S. 2012. Nodal tuberculosis revisited: A review. J. Infect. Dev. Ctries., 6: 6-12.

Jindal, S.K., Aggarwal, A.N., Gupta, D., Ahmed, Z., Gupta, K.B., Janmeja, A.K., et al. 2013. Tuberculous lymphadenopathy: A multicentre operational study of 6-month thrice weekly directly observed treatment. Int. J. Tuberc. Lung Dis., 17: 234-9.

Khan, F.Y. 2009. Clinical pattern of tuberculous adenitis in Qatar: Experience with 35 patients. Scand $J$. Infect. Dis., 41: 128-34.

Koul, A.N., Shah, T., Jan, R.A., Khan, U.H., Koul, P.A. 2012. Gaint Mantoux in Tubercular Lymphadenitis, Pak. $J$. Chest Med., Vol 18, No 4.

Singh, S.K., Tiwari, K.K. 2016. Tuberculous lymphadenopathy: Experience from 
the referral center of Northern India. Niger Med. J., 57: 134-8

WHO. 2015. Tuberculosis. WHO.Global TB Report 2015 Available from: http://www.who.int/tb/publications/glo bal_report/gtbr2015_executive_summ ary.pdf

\section{How to cite this article:}

Munir Ahmad Wani and Ajaz Nabi Koul. 2016. Cervical Tubercular Lymphadenopathy, Clinical Course, Difficulties in Management and Resistance Pattern in Retreatment Cases. Int.J.Curr.Microbiol.App.Sci. 5(12): 654-659. doi: http://dx.doi.org/10.20546/ijcmas.2016.512.073 